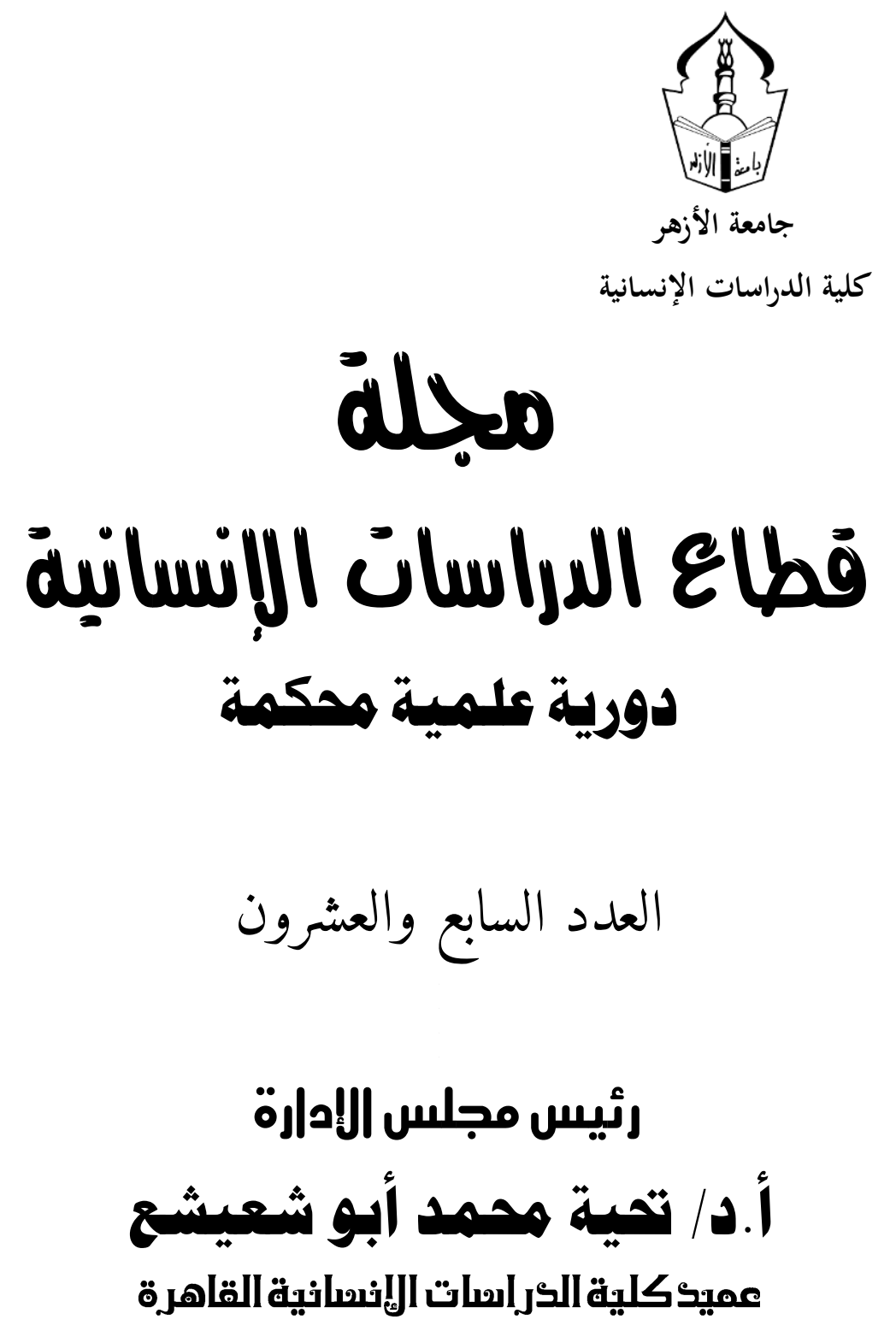

$$
\text { يونيو }
$$




$$
\begin{aligned}
& \text { جامهمة الأزهر } \\
& \text { كلية الدراسات الإنسانية- القاهرة } \\
& \text { ت } \\
& \text { فاكس : PrrATA.VI/ PrrATA.A1 } \\
& \text { r شارع يواسف عباس الحي السابع مدينة نصر القاهرة } \\
& \text { E-mail : Journal.humanities@azhar.edu.eg }
\end{aligned}
$$

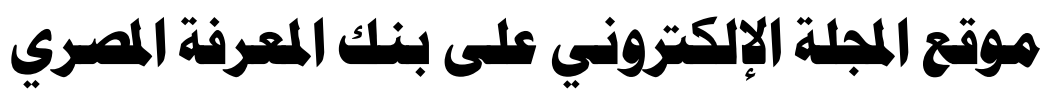

$$
\begin{aligned}
& \text { http://jsh.journals.ekb.eg } \\
& r \cdot q \cdot-9171 \\
& \text { التزقيم الدولي } \\
& \text { ro.--ryar } \\
& r \cdot . r-1 \text { raOA } \\
& \text { التزقيم الدولبي الإلكتزوني } \\
& \text { رقم الإيداع } \\
& \text { بار الحصري للطباعة } \\
& \text {.1.7struvar/A + 1..919019r/A } \\
& \text { تمهت الطباعة } \\
& \text { | بريد إلكتروني }
\end{aligned}
$$




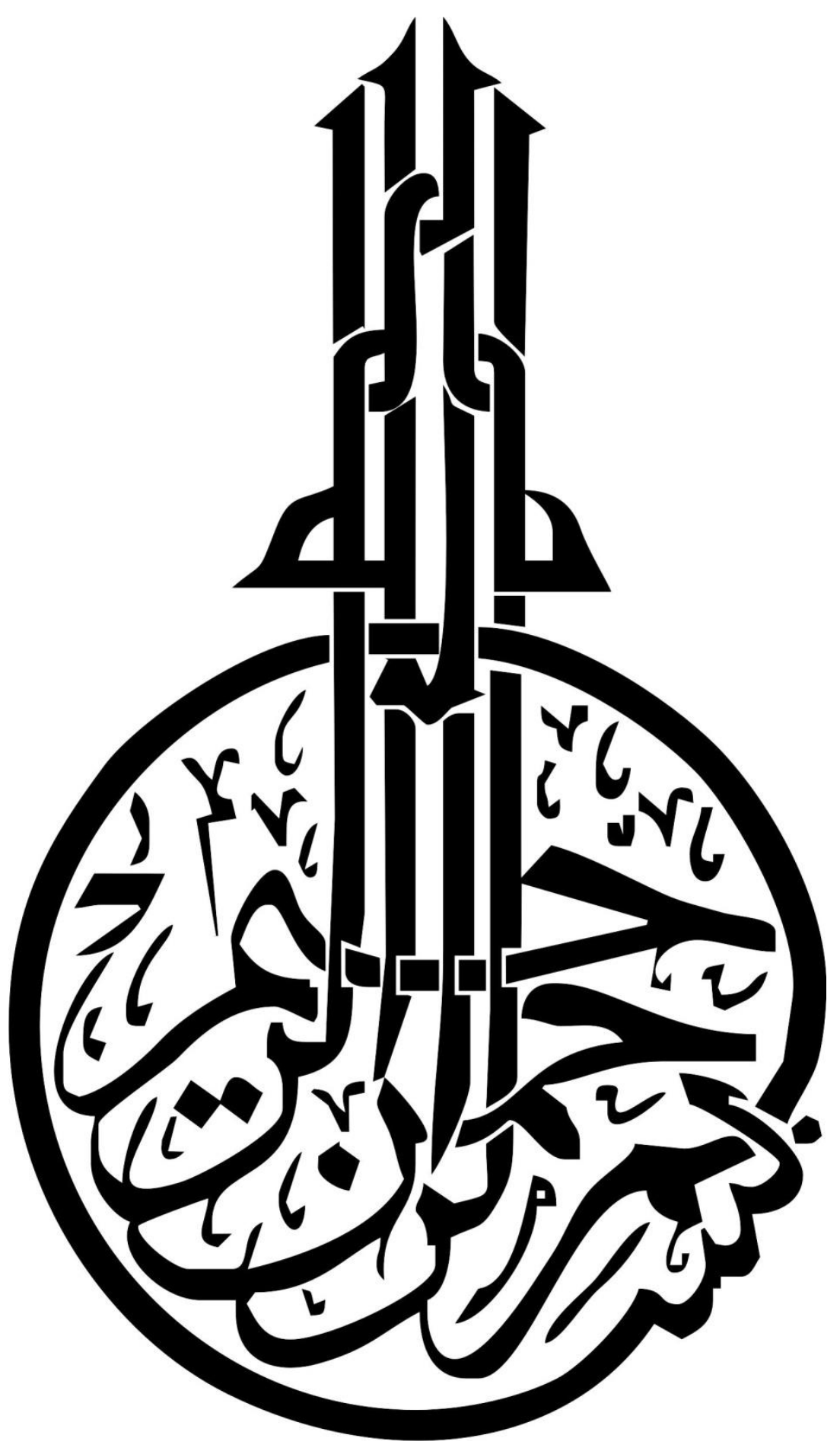





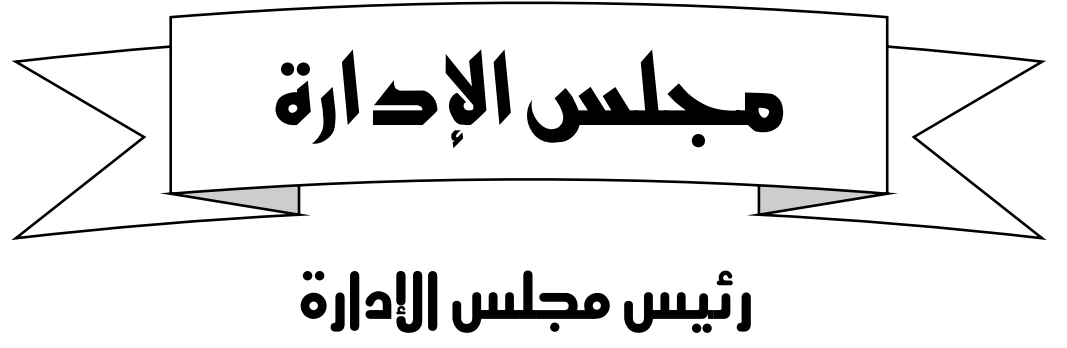

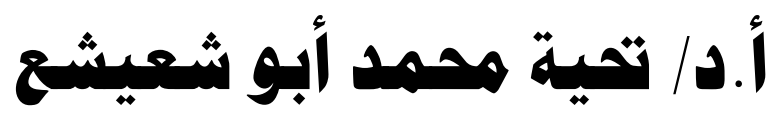

عميد كلية الدراسات الإنساتية القاهرة

أعضصاء مبلس الإدارة

أ.د/ هممد عزت سعيد غازي

عميد كلية اللفات والترجمة القاهرة

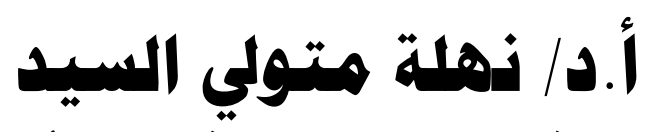

عميد كلية الدراسات الإنسانية تفهنا الأشراف

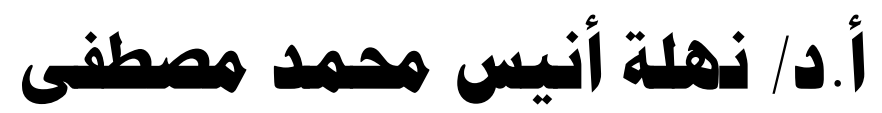

وكيل كلية الدراسات الإنسانية للاراسات العليا والبحوث بالقاهرة

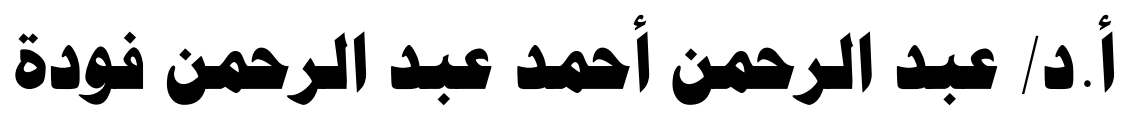

وكيل كلية اللفات و الترجمة للاراسات العليا و البحوث بالقاهرة 



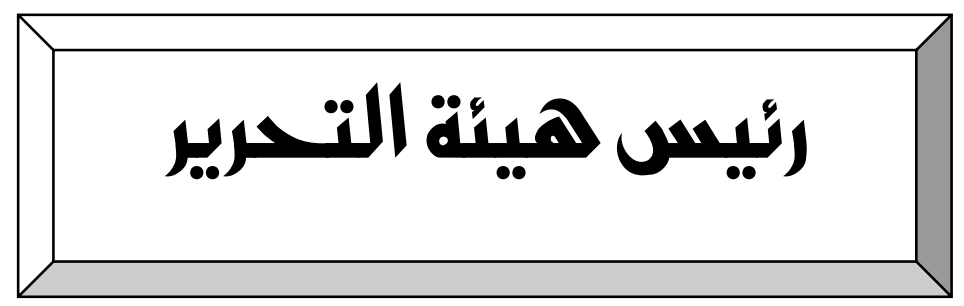

$$
\text { أ. قسم اللغلة الإبراهيمية شعبان }
$$

\section{هيئة التحرير}

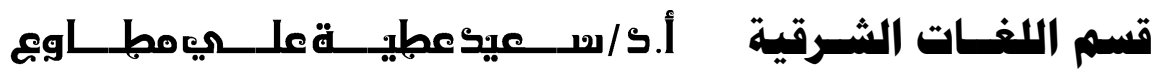

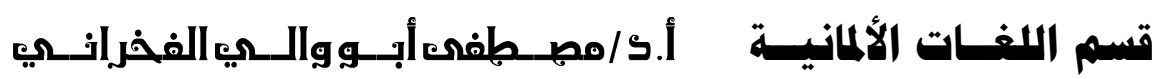

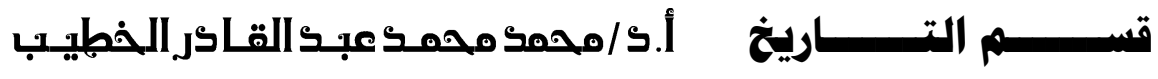

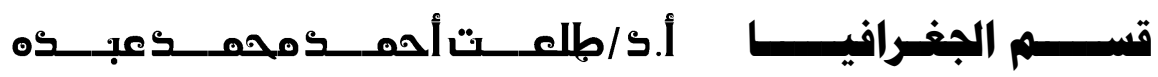

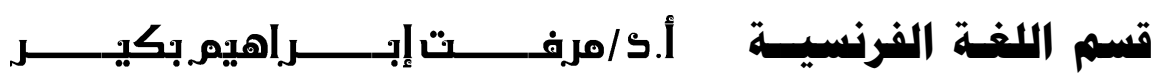

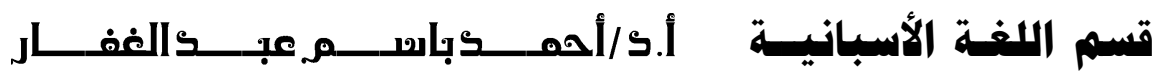

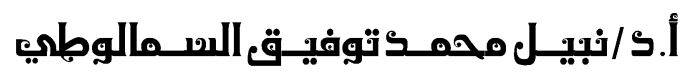

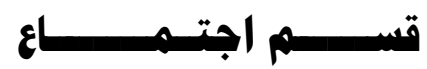

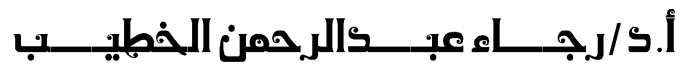

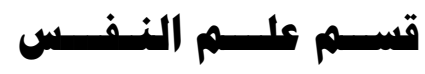

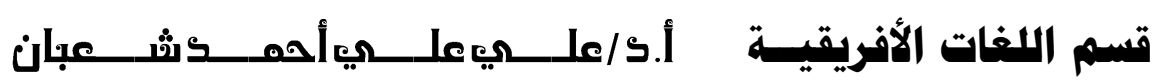




\section{قواعد تقديم البحوث للنشر}

نرجو من السادة الباحثين التكرم بمراعاة القواعد التالية :

- أبعاد ورقة الكتابة على ملف الورد O.

- ترك هوامش بسم من أعلى وأسفل وجهة اليمين وجهة اليسار.

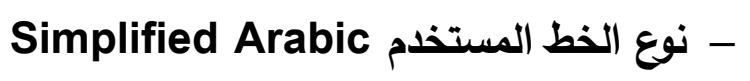

- نوع الخط المستخدم باللغة الإنجليزية فimes New Roman -

يراعى في طريقة الكتابة وهماس وسمك الفط القواعد التالية :

(بالإنجليزية والعربية)

14 Bold عنوان البحث -

14 Bold -

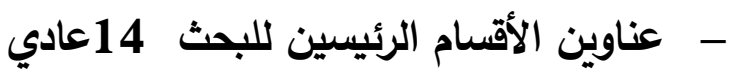

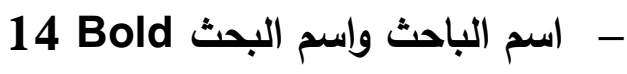

12 Bold - وظائف القائمين بالبحث - متن البحث 14عادي

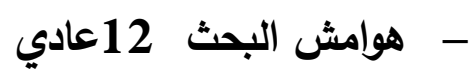
-

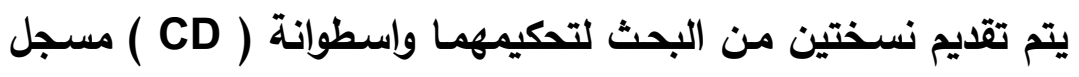

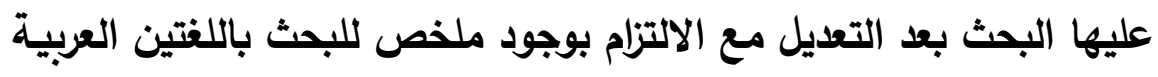

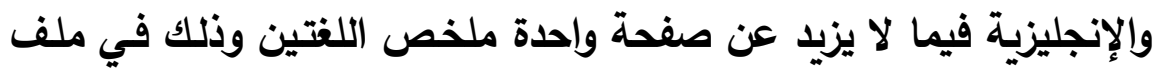




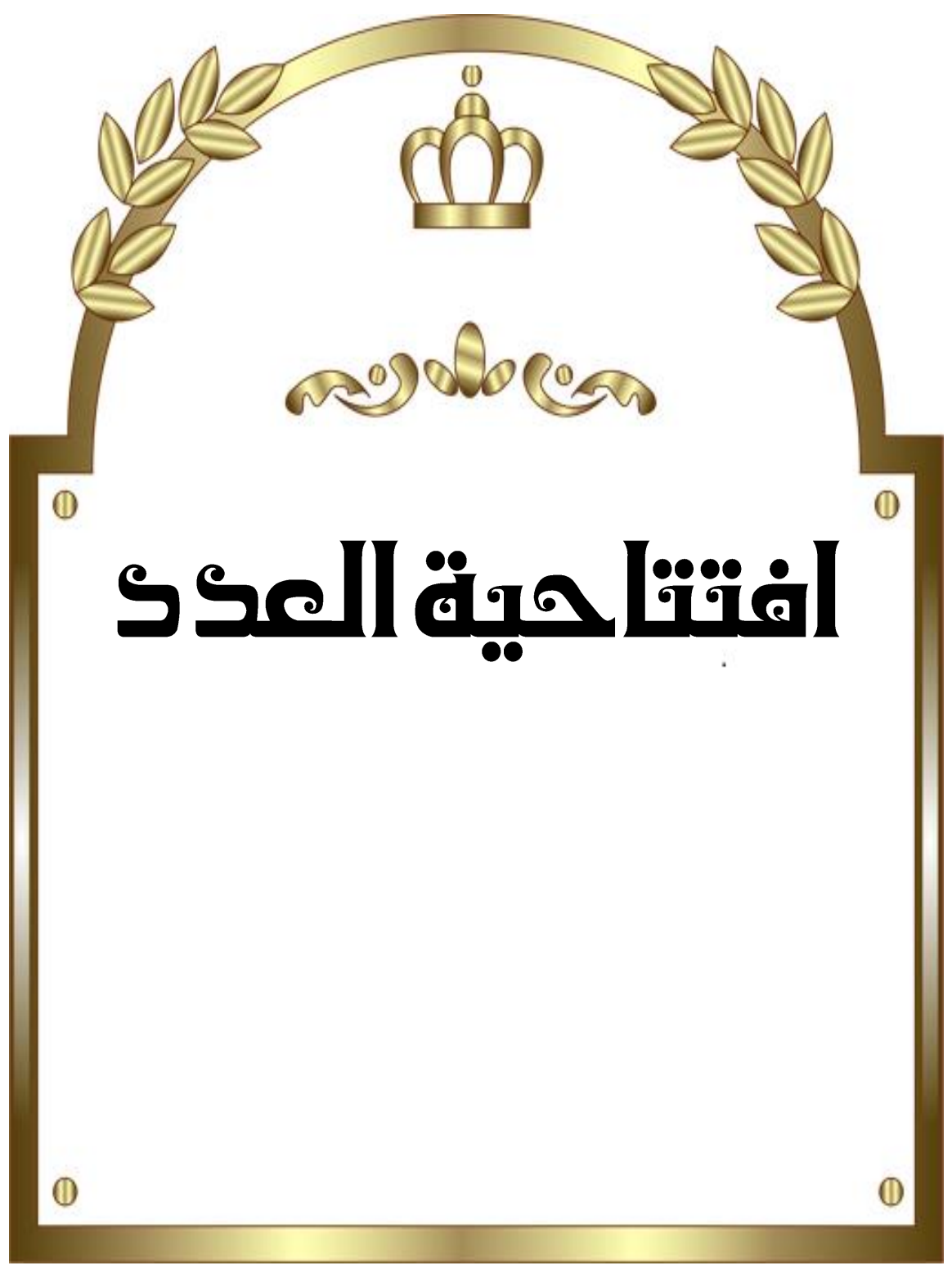





\section{افتتاحية العدد \\ بسم الله الرحمن الرحيم}

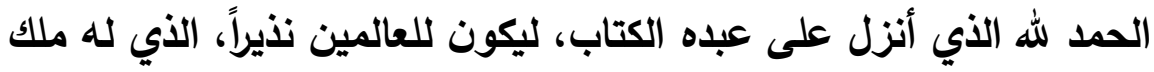

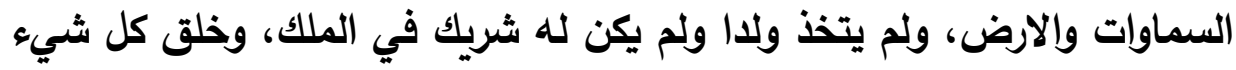

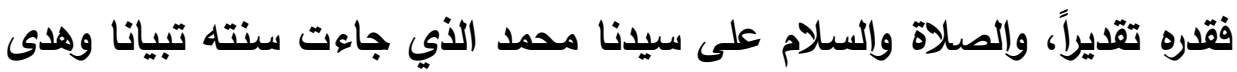
للعالمين، وعلى آله وصحبه أجمعين.

عزيزي القارئ نستقبل معا بحمد الله العدد السابع والعثرين من مجلة قطاع

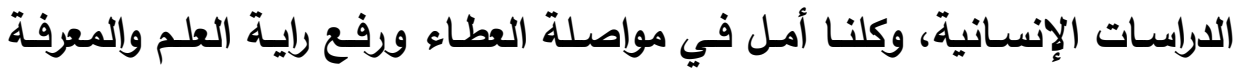
وتعميم الفائدة العلمية بين طلاب العلم والباحثين، ولا جدال أن استمرار نجاح

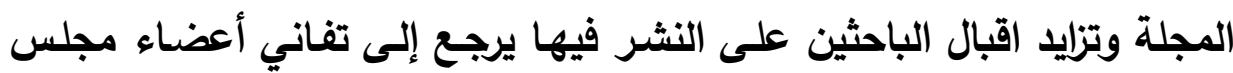
الادارة في خدمة رفعة المجلة المجلة وتيسير النشر فيها. ويتضمن هذا العدد بين دفتيه ثلاثة وثلاثين بحثا مختارًا ومتنوعًا لكوكبة الكاتئ

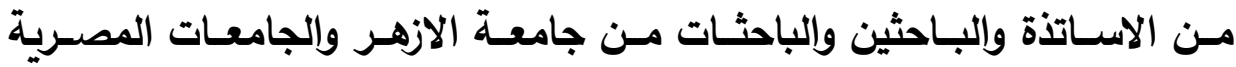

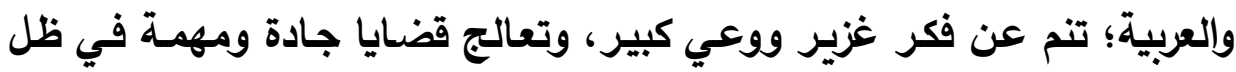

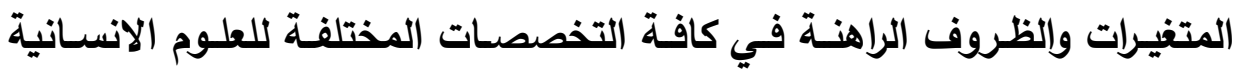

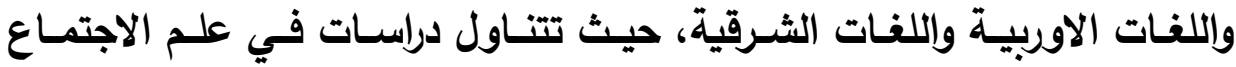

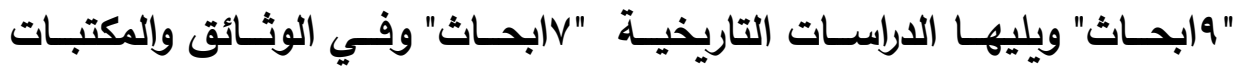

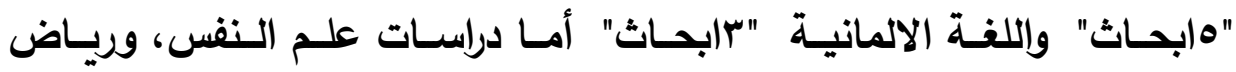

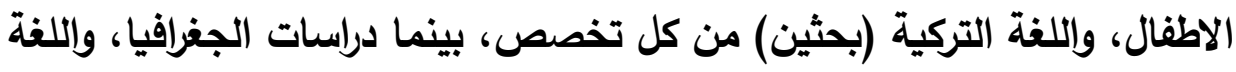
الانجليزية، واللغة العبرية "بحث واحد" فقط من كل تخصص.

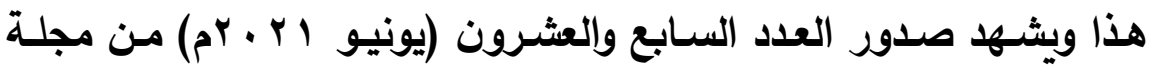

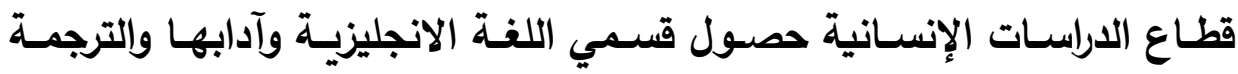


الفورية، واللفة الأسبانية وآدابها على الاعتماد من الهيئة القومية لضمان جودة

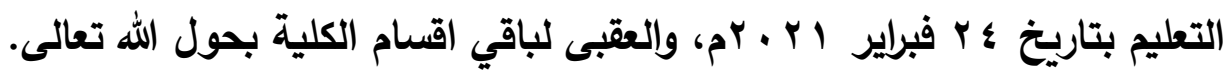

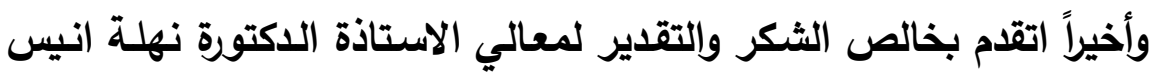
محمد مصطفى وكيلة الكلية للدراسات العليا والبحوث، على ما تبذله من جهود ودعم متواصل للنهوض بالمجلة، والثكر موصـول لفريق العـل مـع سيادتها

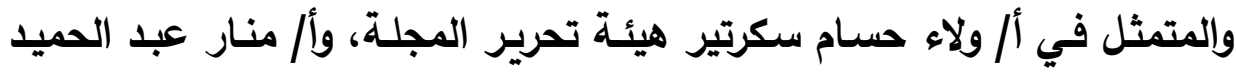

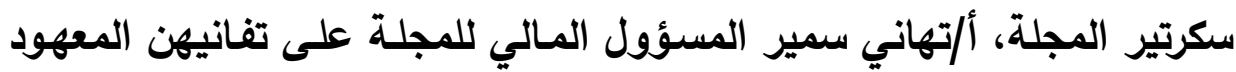
في العمل للخروج بالمجلة في أفضل صورها. وفي الختام نسأل الله تعالى التوفيق والسداد وأخر دعوتنا أن الحمد لله رب الفران العالمين

$$
\text { الأستاذ الدكور }
$$

تصية أبو شعيشر

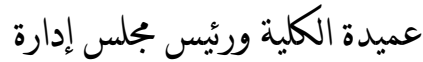

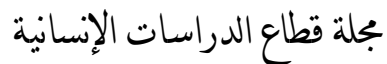




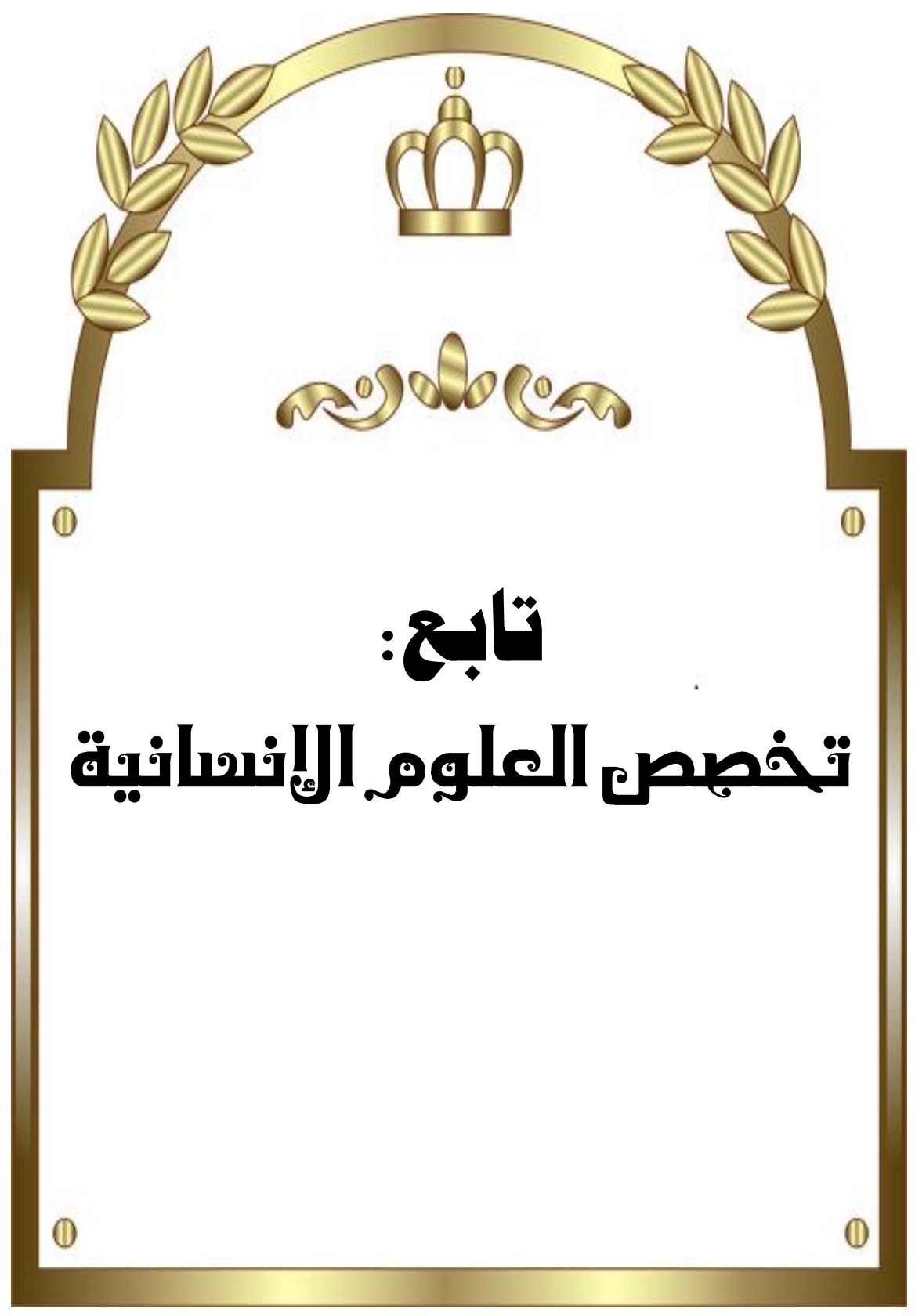





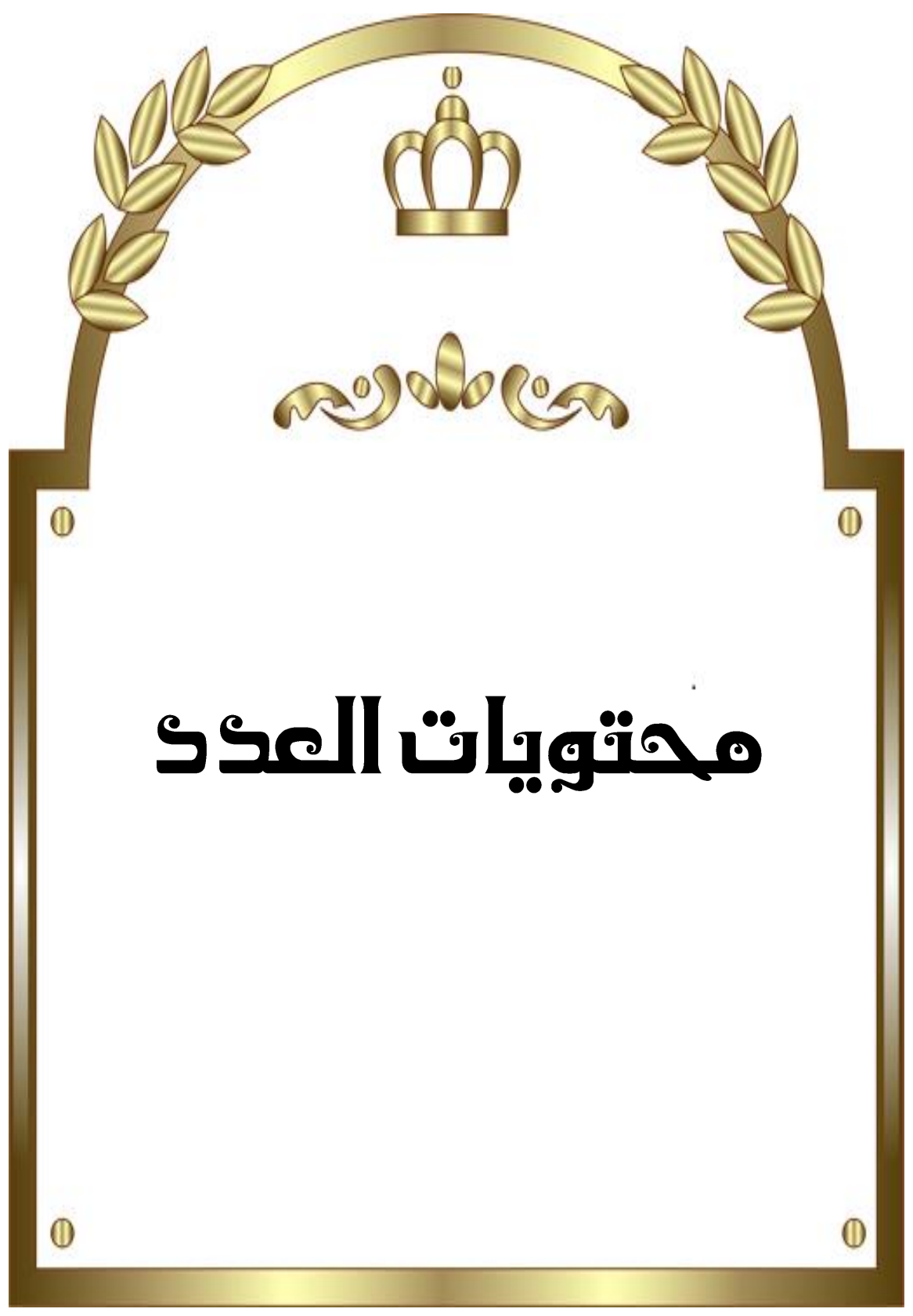





\begin{tabular}{|c|c|c|}
\hline الصـفحـة & الموضدوع & p \\
\hline$|\leq r \varepsilon-1 Y q|$ & 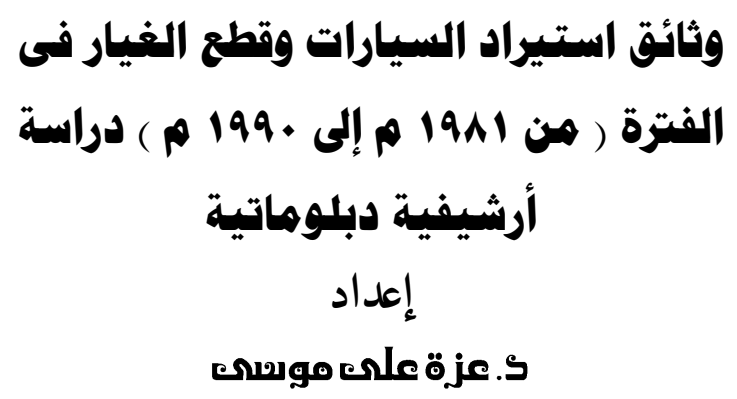 & .11 \\
\hline 10rE_ $1 \leqslant r 0$ & 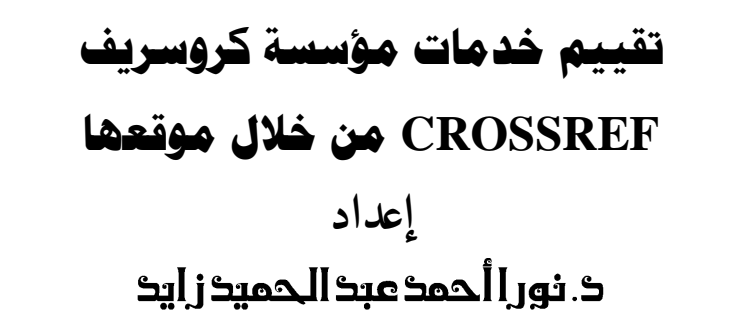 & .19 \\
\hline $10 V Y_{-} 10 Y 0$ & اقتناء الأرشيفات للأشياء المادية المتعلقة &.$r$. \\
\hline $17 r \cdot-10 V r$ & 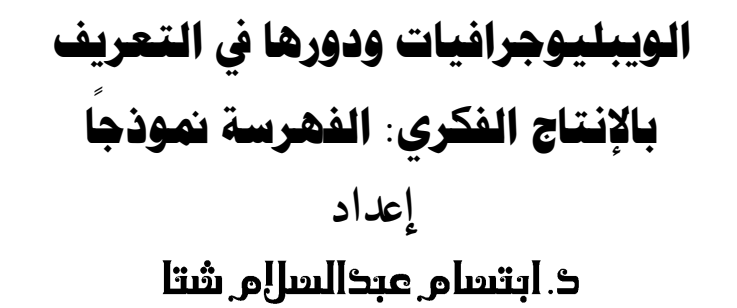 &.$Y^{\prime}$ \\
\hline
\end{tabular}




\begin{tabular}{|c|c|c|}
\hline الهـفحـة & الموضـوع & P \\
\hline $17 V 7-1741$ & 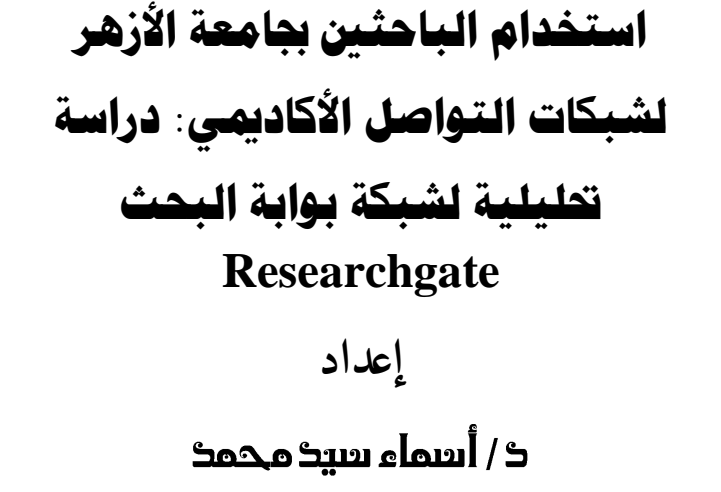 & . YY \\
\hline $1 V \wedge \varepsilon-17 V V$ & 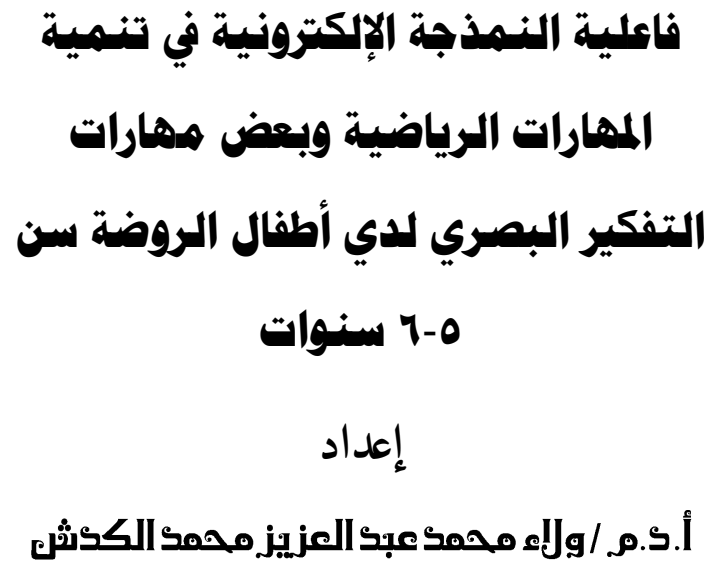 &.$r r$ \\
\hline । $\wedge 9 r_{-} \mid \vee \wedge 0$ & 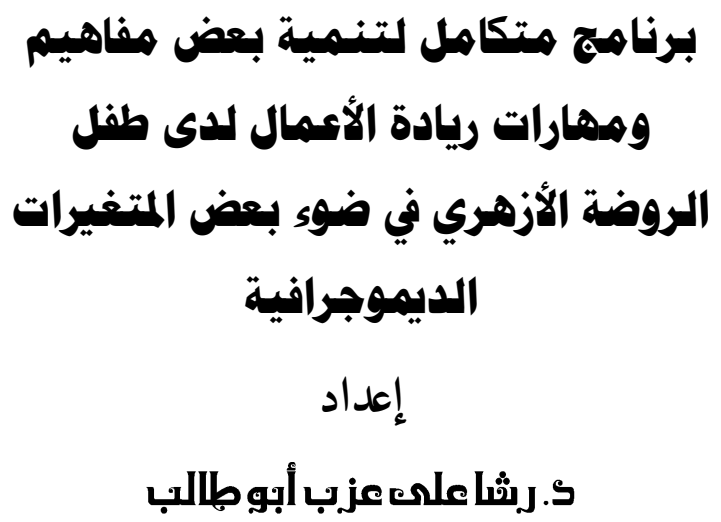 & Y \\
\hline
\end{tabular}




\begin{tabular}{|c|c|c|}
\hline الصـفحـة & الموضـوع & P \\
\hline $199 \wedge-1 \wedge 94$ & للإنجاز والتهافيم الإلكتزونى وعلاقته بالدافعية & .ro \\
\hline$r .9 \varepsilon-1999$ & 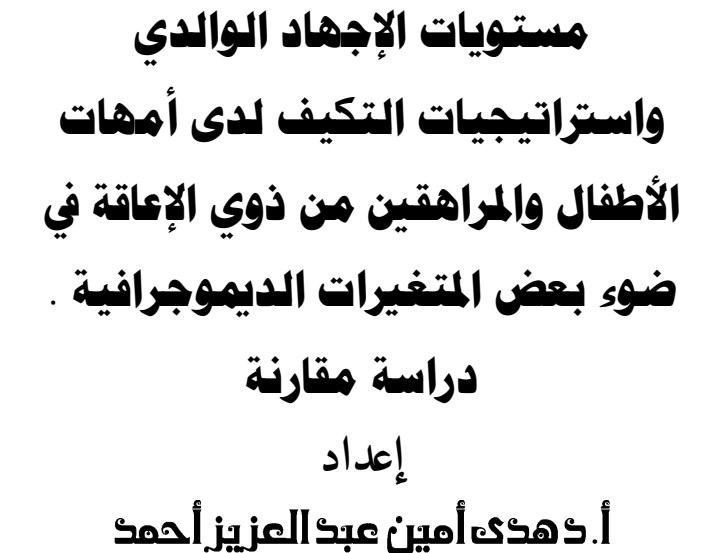 & ד \\
\hline
\end{tabular}





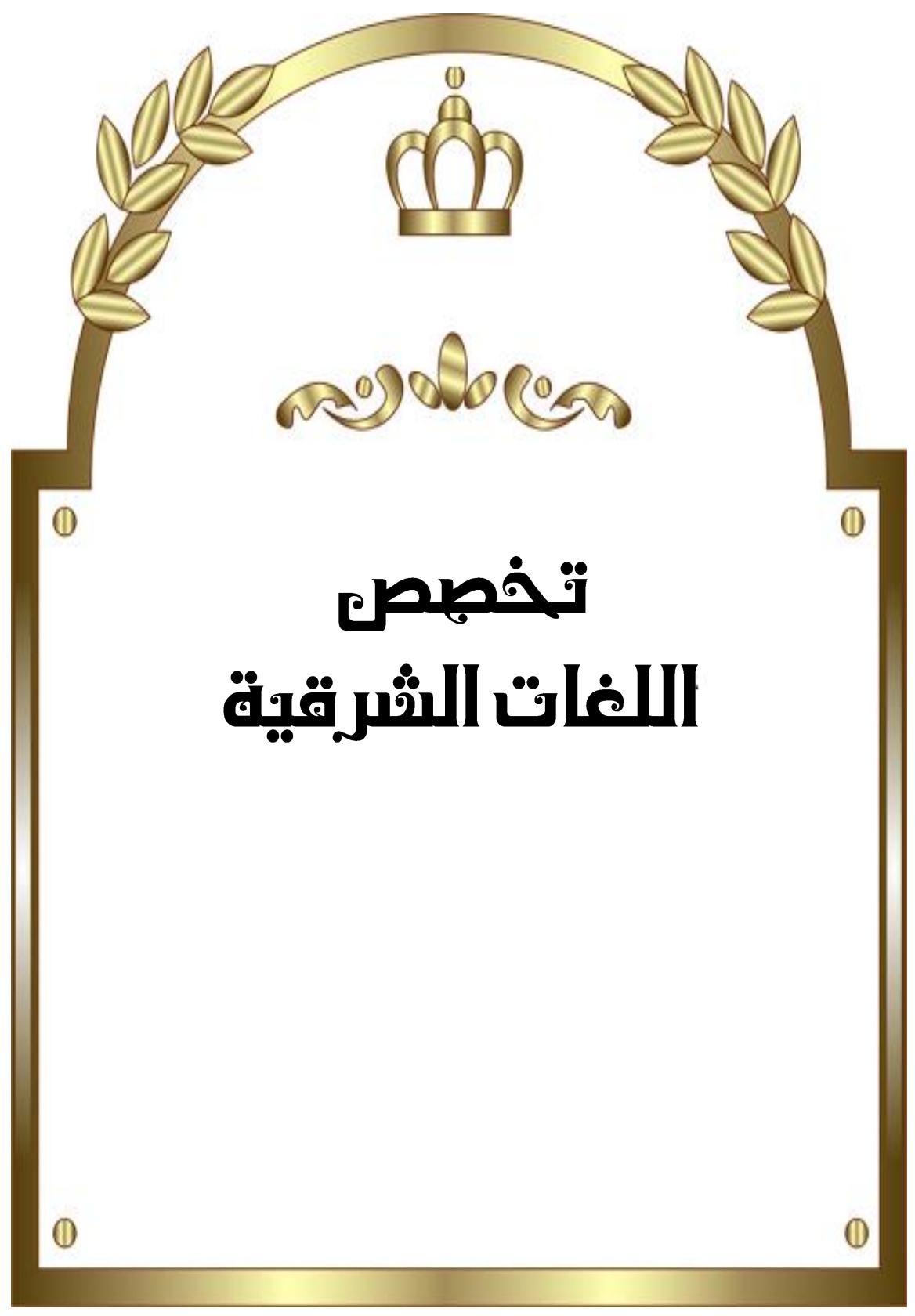





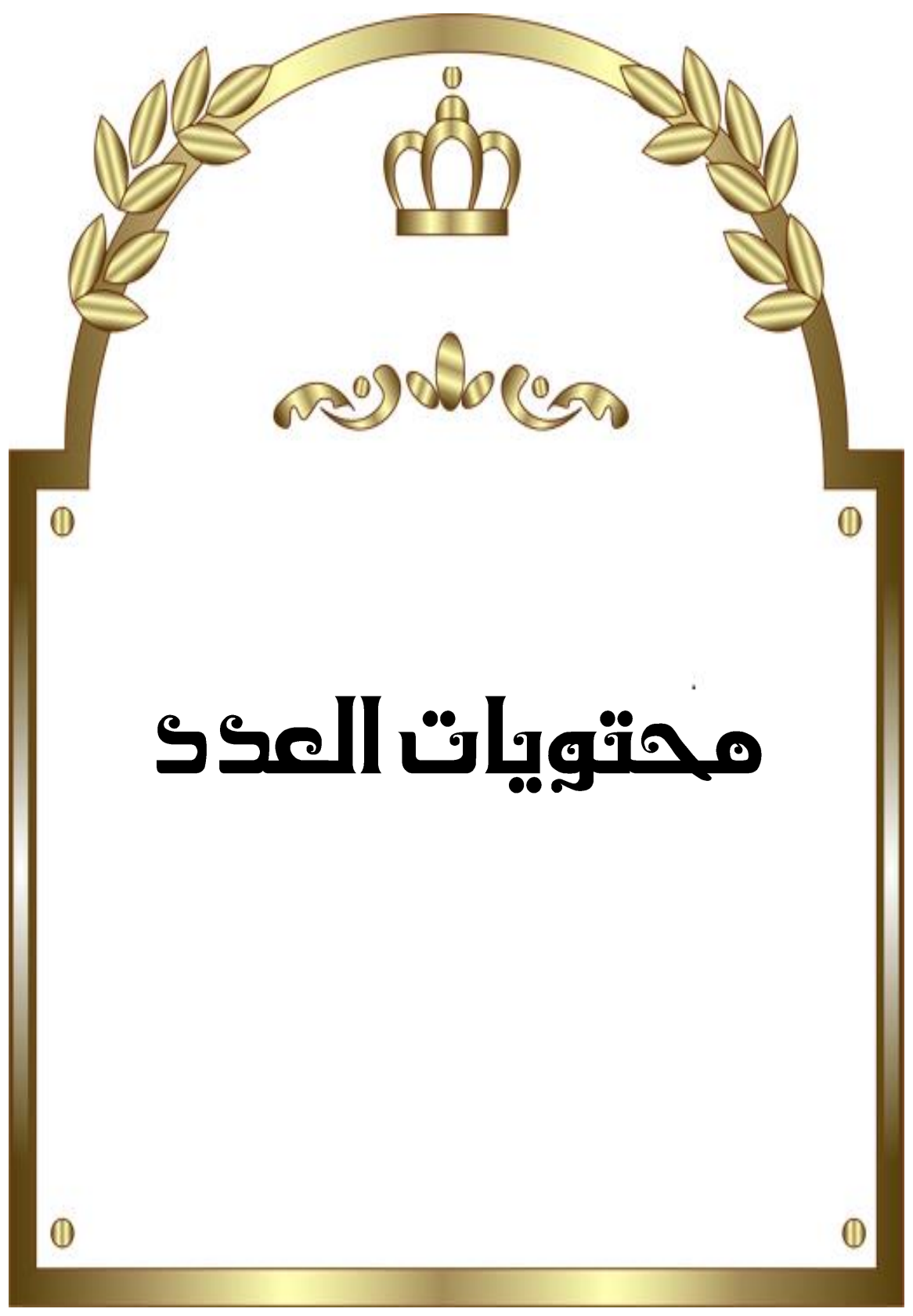





\begin{tabular}{|c|c|c|}
\hline الصسفحة & الموضدوع & P \\
\hline$r 107-r .90$ & 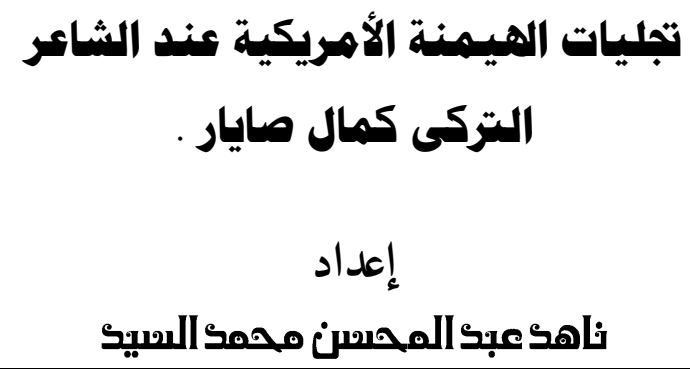 &.$r V$ \\
\hline Y Y A_ YIOV & 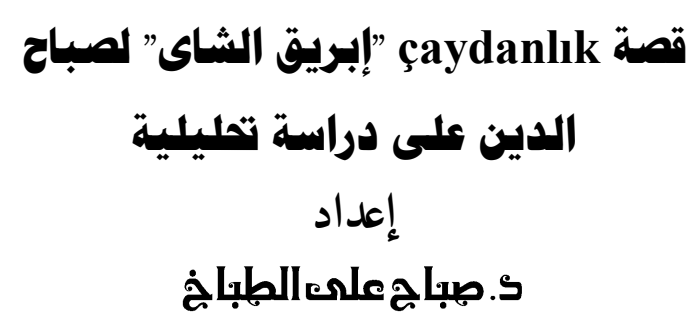 &. $\mathrm{r}$ \\
\hline$r r \Lambda \cdot-r r \mid q$ & 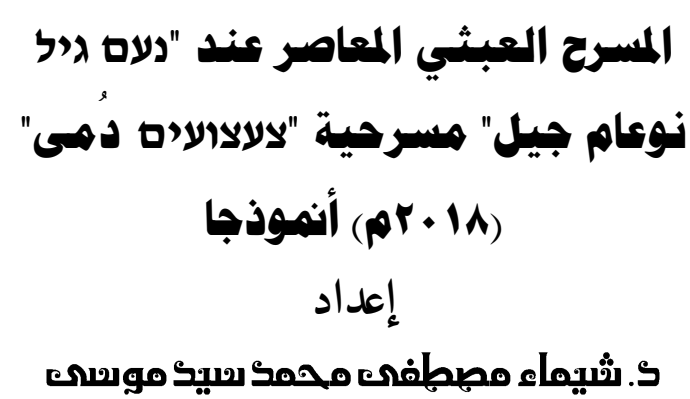 &.$r q$ \\
\hline
\end{tabular}





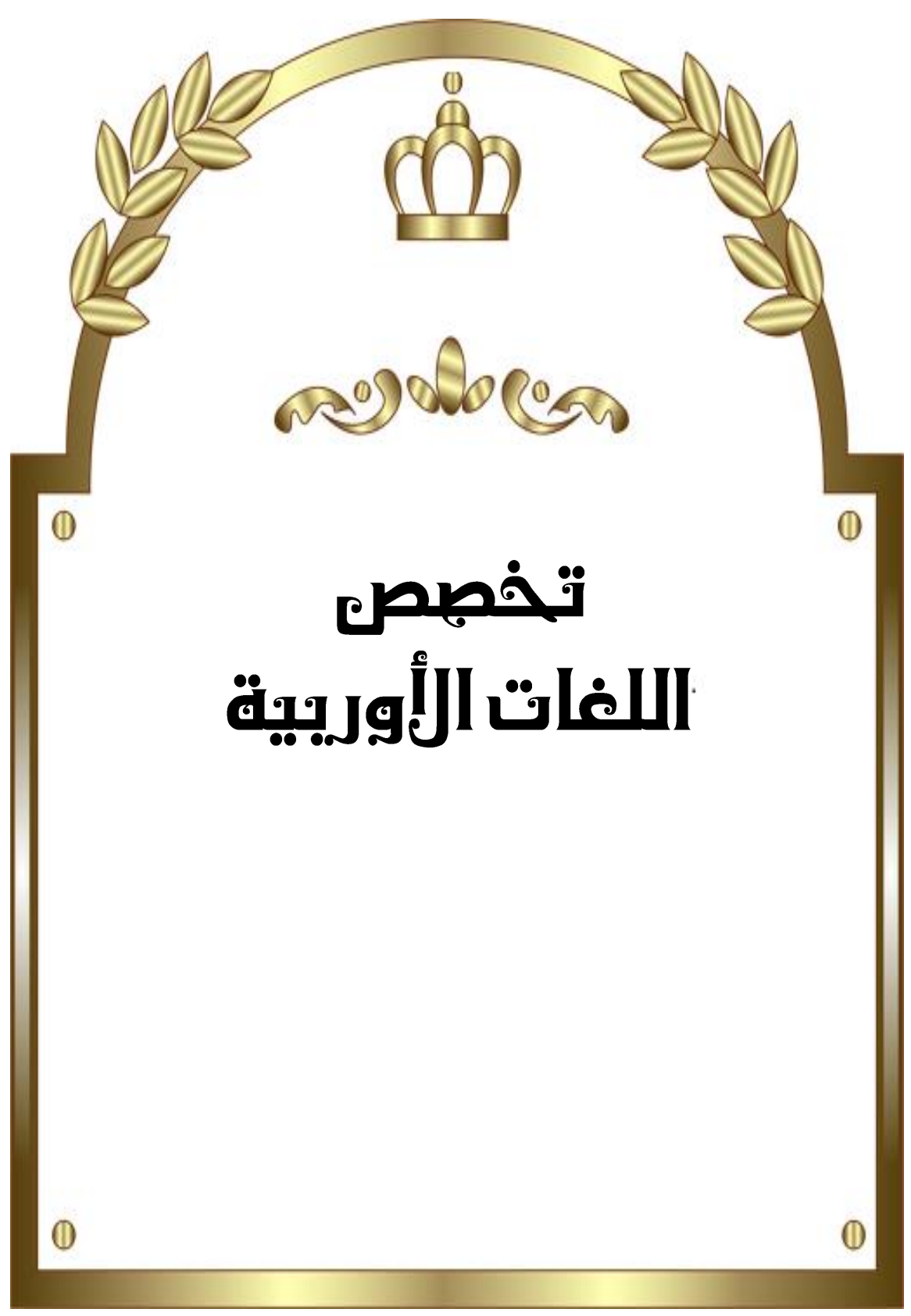





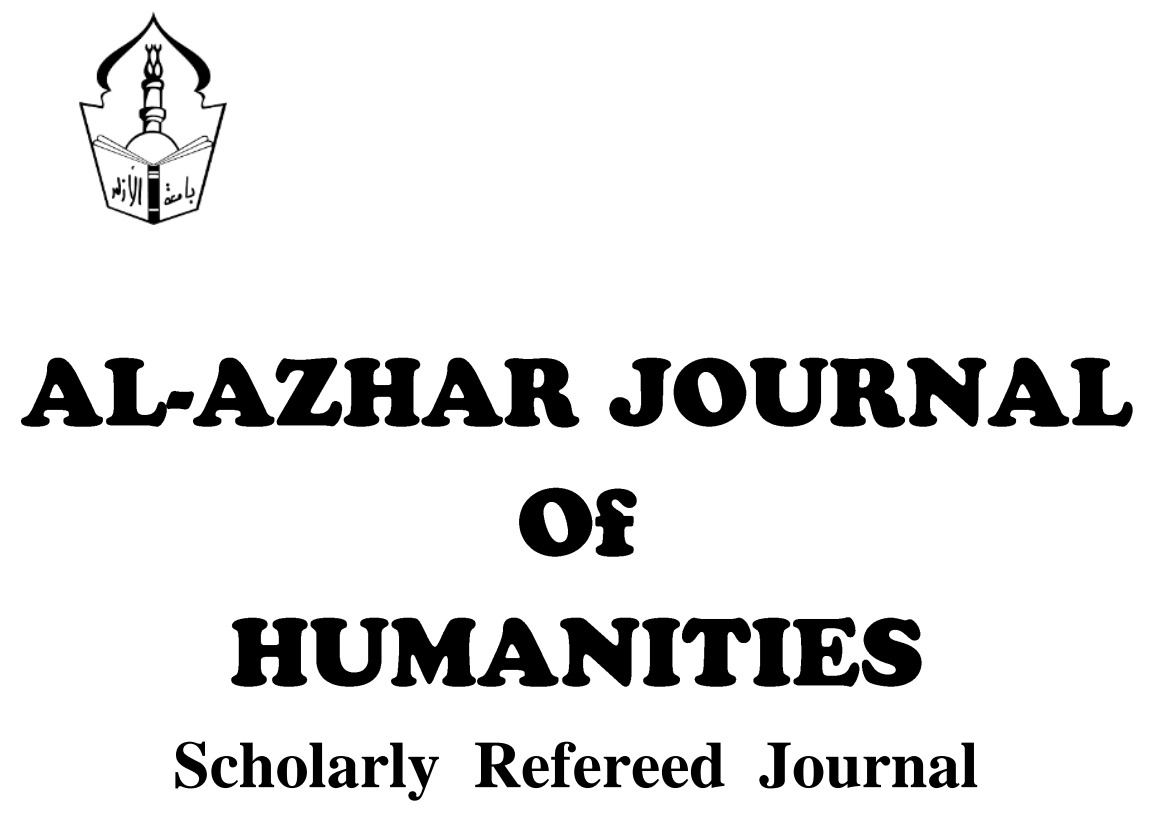

\section{CHAIRMAN}

Prof. Tahia Abu She'sha

Dean of Faculty of Humanities, Cairo

Volume 27

June 2021 



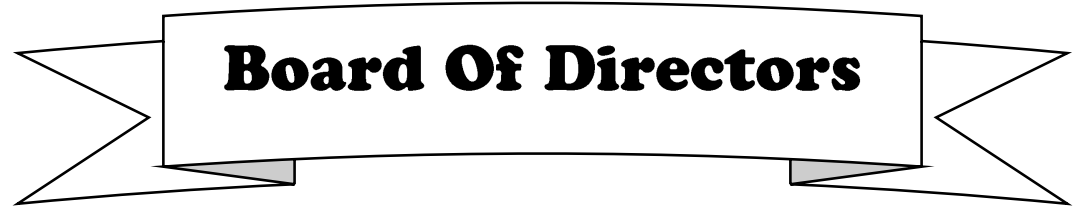

Chairman

Prof. Tahia Muhamad Abu She'sha

Dean of Faculty of Humanities, Cairo

\section{Members of Board of Directors}

\section{Prof. Mohammed Ezzat Saeed Ghazy}

Dean of Faculty of Languages and Translation, Cairo

$$
\text { Prof. Nahla Metwaly El Sayed }
$$

Dean of Faculty of Humanities, Tafahna Al-Ashraf

Prof. Nahla Anis Muhamad Mustafa

Vice Dean of Faculty of Humanities, Cairo

\section{Prof. Abdelrahman Ahmed Fouda}

Vice Dean of Faculty of Languages and Translation, Cairo 



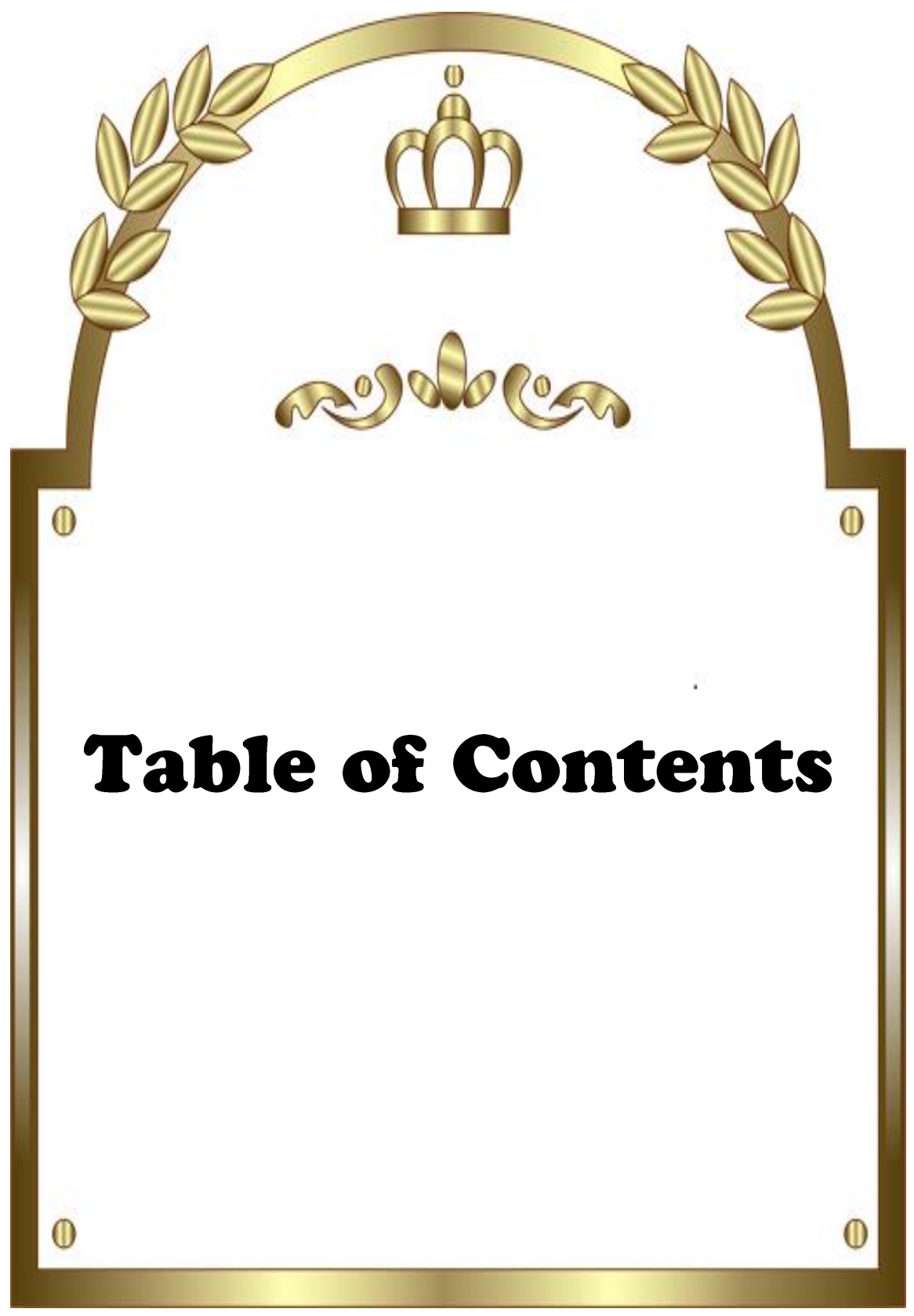





\section{Table of Contents}

\begin{tabular}{|c|c|c|}
\hline No & Title of the Research & Page \\
\hline 1. & $\begin{array}{c}\text { Zum Problem der sprachlichen } \\
\text { Variation beim Übersetzen arabisch- } \\
\text { deutscher Rechtstexte } \\
\text { By } \\
\text { Dr. Reda Hamed Kotb Saad }\end{array}$ & 2283-2312 \\
\hline 2. & $\begin{array}{c}\text { Unreinheit des Hundes im Islam } \\
\text { Eine analytische Studie aus } \\
\text { zeitgenössischer Perspektive } \\
\text { By } \\
\text { Dr. Ismail Abdallah Ismail Ahmed }\end{array}$ & $2313-2360$ \\
\hline 3. & $\begin{array}{l}\text { Pandemic Digital Poetry: An } \\
\text { Analytical Study of Two Selected } \\
\text { Social Media Poems as Examples } \\
\text { By } \\
\text { Dr. Reham Mohammed Abu Zaid }\end{array}$ & 2361-2422 \\
\hline
\end{tabular}


